\title{
Extraction of Phytochemicals from Grains of Paradise Using Supercritical Carbon Dioxide
}

\author{
Maiko Ono $^{1}$, Yukihiro Kawamoto ${ }^{1,2}$, Chiho Uemori ${ }^{1}$, Wahyudiono ${ }^{2}$, Hideki Kanda ${ }^{2}$, \\ and Motonobu Goto, \\ 1 Department of Chemical Engineering, Nagoya University, Furo-cho, Chikusa-ku, Nagoya 464-8603, Japan \\ 2 Maruboshi Vinegar Ascii, Food Technology and Biology of Technical Center (M. A .F. T) 2400 Tabara, \\ Kawasaki-machi, Tagawagun, Fukuoka 827-0004, Japan \\ *E-mail: mgoto@nuce.nagoya-u.ac.jp (Corresponding author)
}

\begin{abstract}
Supercritical carbon dioxide $\left(\mathrm{SCCO}_{2}\right)$ is one of the green methods to extract plant matters substances. In this study, $\mathrm{SCCO}_{2}$ has been applied as a media to extract the grains of paradise seeds substances at temperatures of $40-80{ }^{\circ} \mathrm{C}$ and pressures of $20-40$ MPa using a semi-continuous flow-type system. Results of FT-IR spectra analysis showed that the grains of paradise seeds substances were extracted by $\mathrm{SCCO}_{2}$. The SEM images of the grains of paradise seeds residues also showed that the physical changes of the grains of paradise seeds surface occurred after $\mathrm{SCCO}_{2}$ extraction. The main compounds in extracts were gingerols, shogaols, and paradols. However, the GC-MS may only identify paradol compounds due to gingerols, shogaols, and paradols are homologous series of phenolic ketones and paradols was more stable than gingerols and shogaols. The yields of gingerols, shogaols, and paradols were $9.12,3.90$, and $4.42 \mathrm{mg} / \mathrm{g}$ sample, respectively and affected by extraction temperatures and/or extraction pressures.
\end{abstract}

Keywords: $\mathrm{SCCO}_{2}$ extraction, grains of paradise, gingerols, shogaols, paradols.

ENGINEERING JOURNAL Volume 21 Issue 4

Received 17 December 2016

Accepted 24 January 2017

Published 31 July 2017

Online at http://www.engj.org/

DOI:10.4186/ej.2017.21.4.53 


\section{Introduction}

The genus Zingiberaceae contains between 40 and 50 species perennial herbs, native to Africa. As one of Zingiberaceae species, grains of paradise (Aframomum melegueta [Rosco] K. Schum.) generally referred to as guinea grains or alligator pepper or melegueta pepper is a perennial herb with short rhizomes from which arise distinct leafy shoots, $1.5-2 \mathrm{~m}$. Grains of paradise is native to West Africa, and cultivated in Ghana, Guinea, the Ivory Coast, Nigeria and Sierra Leone [1]. The seeds of grains of paradise, source of melegueta pepper, are used as a spice for flavoring food and have wide range of ethnobotanical uses.

Phenolic compounds are known as the most abundant secondary metabolites of plants. These compounds were a phytochemicals group which have a phenol structure and considered as important determinants in the nutritional and the quality of fruits, vegetables, other plant foods, and food preparations. Phenolic compounds were widely found in the plant world and commonly involved in defense toward ultraviolet radiation or attack by pathogens, parasites, and predators [2]. Hence, these compounds play an important role in plant growth and offer the plants to have excellent properties as food preservatives. Phenolic compounds were also affect to the color and contribute to sensory characteristics of vegetables and fruits [3]. Due to these properties, phenolic compounds become suitable for various industrial applications such as natural colorants and preservatives for foods or in the production of paints, paper, and cosmetics. As one of the spice plants, grains of paradise was also contained of phenolic compounds such as gingerols, shogaols, and paradols $[4,5]$. These phenolic compounds have various biological properties especially in anti-inflammatory, anti-oxidant and anti-tumor effects. As one of potent nutraceuticals, 6-gingerol had a variety of pharmacological abilities and has been known to have antihyperglycemic, anti-cancer and anti-oxidative properties [6]. 6-shogaol also was known as antiproliferative, anti-metastatic, and pro-apoptotic activities via suppression of STAT3 gene products in tumor tissues [7]. It effectively decreased survival and affected apoptosis process in human and mouse prostate cancer cells via inhibition of STAT3 and NF- $\mathrm{KB}$ activities. Compared with 6 -paradol which found in grains of paradise seeds, 6-shogaol was more effective [8]. 6-shogaol may also prevent the growth of human pancreatic tumors and has a high responsive to gemcitabine by suppressing inflammatory pathways linked to tumorigenesis [9].

In the present work, supercritical carbon dioxide $\left(\mathrm{SCCO}_{2}\right)$ was employed as a solvent extraction [10-14] to extract phenolic compounds from grains of paradise seeds. The $\mathrm{SCCO}_{2}$ extraction technique is very advantageous and environmentally friendly compared with other conventional extraction technique, such as soxhlet extraction technique. Due to its high diffusivity combined with its high solvent strength that can be easily tuned by changing of temperature and/or pressure, $\mathrm{SCCO}_{2}$ became an attractive extraction medium. At room temperature and ambient pressure, $\mathrm{CO}_{2}$ has gaseous phase so it can be easily separated and recycled as the solutes dissolved in the $\mathrm{SCCO}_{2}$ will precipitate upon depressurization. Accordingly, supercritical fluid extraction including $\mathrm{SCCO}_{2}$ may offer appropriate technique for extraction and fractionation seem to be promising for the food and pharmaceutical industries and to be more efficient extraction fluids than traditional liquid solvents [14].

\section{Experimental Section}

\subsection{Materials}

Dried seeds of grains of paradise were obtained from south of Nigeria. Prior to extraction, the seeds were ground with a grinder (IKA, MF-10-B-S1, USA) into certain particle size and passed through fine-mesh sieves (MF-Sieb $0.25 \mathrm{~mm}$, Germany). 6-gingerol $\left(\mathrm{C}_{17} \mathrm{H}_{26} \mathrm{O}_{4} ; 98 \%\right)$ and 6-shogaol $\left(\mathrm{C}_{17} \mathrm{H}_{24} \mathrm{O}_{3} ; 98 \%\right)$ were obtained from Tokiwa Phytochemical Co., Ltd (Tokyo, Japan) and 6-paradol $\left(\mathrm{C}_{17} \mathrm{H}_{26} \mathrm{O}_{3}\right)$ with purity of $98.0 \%$ was purchased from Medchemexpress (MCE) LLC, USA. Ethanol $\left(\mathrm{C}_{2} \mathrm{H}_{6} \mathrm{O} ; 99.5 \%\right)$ was purchased from Nacalai Tesque (Japan) and acetonitrile $\left(\mathrm{C}_{2} \mathrm{H}_{3} \mathrm{~N}\right.$; HPLC grade) obtained from Wako Pure Chemicals Industries Ltd., Japan. All chemicals were used without further purification. Carbon dioxide $\left(\mathrm{CO}_{2}: 99 \%\right)$ was supplied by Sogo Kariya Sanso, Inc. Japan. 


\subsection{Experimental Setup and Procedure}

Figure 1 showed the schematic diagram of $\mathrm{SCCO}_{2}$ extraction apparatus which used in these experiments. The apparatus includes a high-pressure pump for $\mathrm{CO}_{2}$ (PU-2086; Jasco, Japan), a heating chamber (WFO400; EYELA, Tokyo, Japan), a $10 \mathrm{~mL}$ extraction cell (Thar Technologies, Inc., PA, USA) and back pressure regulator (AKICO, Tokyo, Japan). In this work, the extraction of 6-gingerol, 6-shogaol, and 6-paradol from grains of paradise seeds by $\mathrm{SCCO}_{2}$ was carried at temperatures of $40-80{ }^{\circ} \mathrm{C}$ and pressures of $20-40$ $\mathrm{MPa}$ using a semi-continuous flow-type system with $\mathrm{CO}_{2}$ flow rate of $3 \mathrm{~mL} \mathrm{~min}^{-1} .1 .0 \mathrm{~g}$ of dried grains of paradise seeds were placed into the extractor, the glass beads were also filled at the bottom and top of the extractor in each experiment. The extractor was put in the heating chamber to keep the operating temperature. The extraction process can be explained briefly as follow. The dried grains of paradise seeds were filled into the extractor and put in the chamber. After the temperature at chamber heater achieved to the desired temperature, $\mathrm{CO}_{2}$ from a cylinder was firstly liquefied and then pumped into the extractor. In all experiments, the extraction products which trapped in $10 \mathrm{ml}$ ethanol were collected for $180 \mathrm{~min}$, weighed and directly stored in the refrigerator at $5{ }^{\circ} \mathrm{C}$. The bottles used for the collection of extracts were wrapped in aluminum foil. These processes were done until analysis.

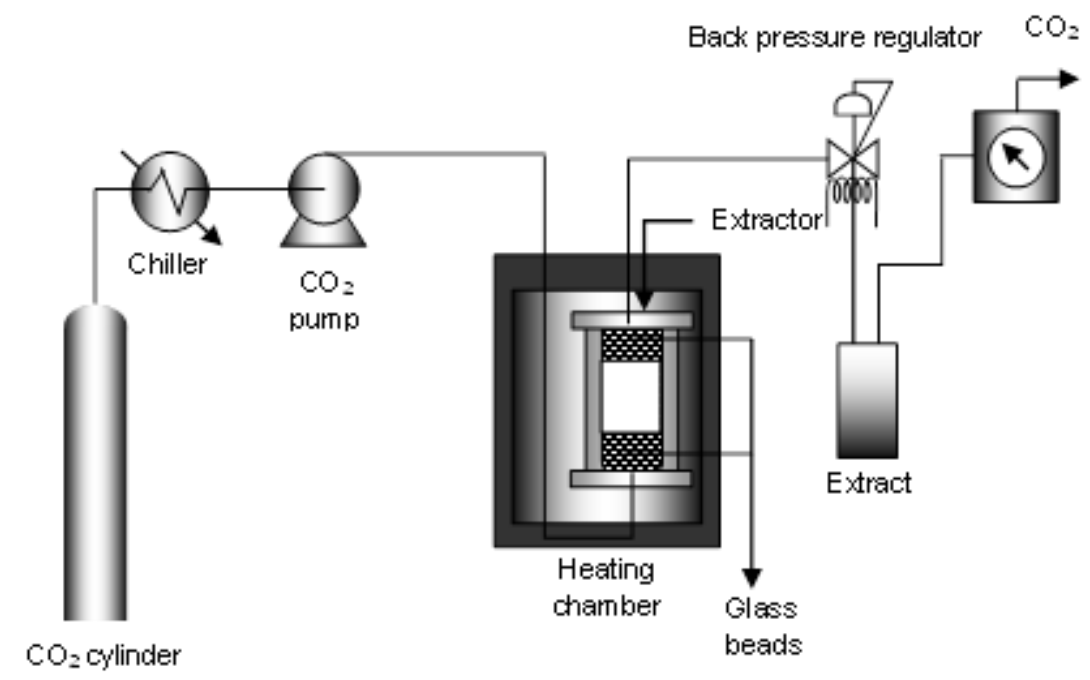

Fig. 1. Schematic diagram of $\mathrm{SCCO}_{2}$ extraction system.

\subsection{Analytical Methods}

Extracted polyphenolic compounds in the extracts were identified by GC-MS (HP model 6890 series GC system and 5973 mass selective detector) with a HP-5 MS capillary column (J\&W Scientific, length $30 \mathrm{~m}$, i.d. $0.32 \mathrm{~mm}$, film thickness $0.25 \mu \mathrm{m}$ ). The temperature program was $1.0 \mathrm{~min}$ at $45^{\circ} \mathrm{C}, 5{ }^{\circ} \mathrm{C} / \mathrm{min}$ to $270{ }^{\circ} \mathrm{C}$, and $10 \mathrm{~min}$ at $270{ }^{\circ} \mathrm{C}$. Helium carrier gas was used at a flow rate of $1.5 \mathrm{~mL} / \mathrm{min}$. The NIST (National Institute of Standards and Technology) library of mass spectroscopy was used for identification of the compounds. Quantitavely, extracted polyphenolic compounds in the extracts were analyzed by HPLC LC10AD equipped with Diode Array Detector SPD-M10A (Shimadzu, Japan). $10 \mu \mathrm{l}$ of extract dissolved in ethanol was injected by SIL-10AF auto-sampler (Shimadzu, Japan) and separated with a STR ODS II column $(5 \mu \mathrm{m}$; 4.6 x $250 \mathrm{~mm}$; Shinwa Chemical Industries, Ltd., Japan) at room temperature. Elution was obtained by using the following gradient steps of solvents A (water) and B (acetonitrile): 0-25 min, 90\% B; $25-30 \mathrm{~min}, 100 \% \mathrm{~B} ; 30-40 \mathrm{~min}, 30 \% \mathrm{~B}$ at a flow rate of $1 \mathrm{ml} / \mathrm{min}$. All analyses were carried out under isothermal conditions at 40 oC. 6-gingerol, 6-shogaol, and 6-paradol were detected at wavelength of 280, 280 , and $220 \mathrm{~nm}$, respectively. Solid residues collected at each operating temperature were dried overnight in the oven at $60^{\circ} \mathrm{C}$. Then, they were characterized by using a Spectrum Two FT-IR spectrophotometer (Perkin-Elmer Ltd., England), in order to determine their structure following $\mathrm{SCCO}_{2}$ treatment. Spectra were measured in attenuated total reflectance (ATR) mode (golden single reflection ATR system, P/N 10500 series, Specac) at $4 \mathrm{~cm}^{-1}$ resolution. The scanning wave number ranged from 4000 to $400 \mathrm{~cm}^{-1}$. The 
morphologies of the grains of paradise seeds before and after treatment by $\mathrm{SCCO}_{2}$ were also observed by using a scanning electron microscope (SEM; JEOL JSM-6390LV).

\section{Results and Discussion}

In order to understand the change of grains of paradise seeds functional groups during extraction process, the grains of paradise seeds before and after $\mathrm{SCCO}_{2}$ extraction process were subjected into an infrared spectrometer. Here, the grains of paradise seeds that remained after $\mathrm{SCCO}_{2}$ treatment is referred to as solid residue; the solid residue at each extraction condition was then characterized by infrared spectroscopy in the wavenumber region of $4000-400 \mathrm{~cm}^{-1}$. Figures 2 and 3 showed the spectral features of grains of paradise seeds and its solid residue after treatment by $\mathrm{SCCO}_{2}$ at various extraction conditions. Similar to other plant biomass, the chemical compositions of grains of paradise seeds are fairly similar although with different magnitudes of components. The major components of them are cellulose, hemicellulose and lignin. Therefore, the same spectral characteristics of grains of paradise seeds and their solid residues were found. These spectral characteristics also showed that the $\mathrm{SCCO}_{2}$ extraction treatment on the grains of paradise seeds does not change the distribution of their functional groups. However, since the removing or reducing grains of paradise seeds components occurred during extraction process, the different peak intensities of them could be found obviously. It indicated that $\mathrm{SCCO}_{2}$ may extract the chemical compounds from grains of paradise seeds [14-17].

Extraction, in principle, could be expressed as the removal of soluble substances from an insoluble materials, either liquid or solid, by treatment with a liquid solvent. The process might happen when the solvent is flowed in the plants matter at high pressures and/or high temperatures. So, the extraction process will also occur when the carbon dioxide was flowed into the plant materials at high temperatures and/or high pressures due to the change of solvent power that can have a strong influence on extraction process $[14,18,19]$. Figure 2 showed the FT-IR spectra of grains of paradise seeds and their solid residues after treatment by $\mathrm{SCCO}_{2}$ when the extraction processes were conducted at various extraction pressures with a constant temperature. This figure clearly revealed that the compositional changes in the each sample (grains of paradise seeds and their solid residues) after applied $\mathrm{SCCO}_{2}$ extraction. The intensities of several functional groups in the grains of paradise seeds decreased after treatment by $\mathrm{SCCO}_{2}$. Table 1 showed the typical functional groups and the infrared signal with the possible compounds [20,21]. The intensity of the broad band located at $3305 \mathrm{~cm}^{-1}$ which was attributed to $\mathrm{O}-\mathrm{H}$ stretching of hydrogen-bonded hydroxyl groups and the band at $2925 \mathrm{~cm}^{-1}$ was representative of $\mathrm{C}-\mathrm{H}$ stretching became decline and narrow after applied $\mathrm{SCCO}_{2}$ extraction. This indicated that they have been removed during the application of $\mathrm{SCCO}_{2}$ extraction treatment on the grains of paradise seeds. The same phenomenon was also found in other functional groups. As shown in the Fig. 2, the intensities of them decreased obviously after treatment by $\mathrm{SCCO}_{2}$. It is well known that the extraction temperature and/or pressure are two most important parameters in the $\mathrm{SCCO}_{2}$ due to it was the major determinants of solvent power that could have a strong effect on effectivity of extraction process. Herrero et al. 2010 [22] informed that an increase in extraction temperature at constant extraction pressure leads to a decrease in the density of the $\mathrm{SCCO}_{2}$ and thus its solvatation capacity, nevertheless, an increase in extraction temperature was followed by an increase in vapour pressure of solutes, resulting in a high solubility in the $\mathrm{SCCO}_{2}$. As a result, the grains of paradise seeds components were extracted easily by $\mathrm{SCCO}_{2}$ at a higher extraction temperature.

Similar to extraction temperature, extraction pressure is also a dominant parameter in the $\mathrm{SCCO}_{2}$ extraction system. An increase in extraction pressure at a constant extraction temperature promotes to increasing the density of $\mathrm{SCCO}_{2}$; at the same time, the diffusion coefficient of $\mathrm{SCCO}_{2}$ decreased. A decrease in the $\mathrm{SCCO}_{2}$ diffusion coefficient leads to a lower ability of the $\mathrm{CO}_{2}$ to penetrate the grains of paradise seeds causing a decrease in the extraction efficiency. However, an increase in the density of the $\mathrm{SCCO}_{2}$ extraction system leads to an increase of its solvating power, thus the enhancement of the extraction efficiency might be occurred. As shown in the Fig. 3, the intensities of functional groups in the grains of paradise seeds also decreased after treatment by $\mathrm{SCCO}_{2}$ at a constant extraction temperature with the elevating extraction pressures [22]. Judging from these results, it could be said that the changing of extraction temperature and/or pressure could give a strong influence on $\mathrm{SCCO}_{2}$ extraction system. 


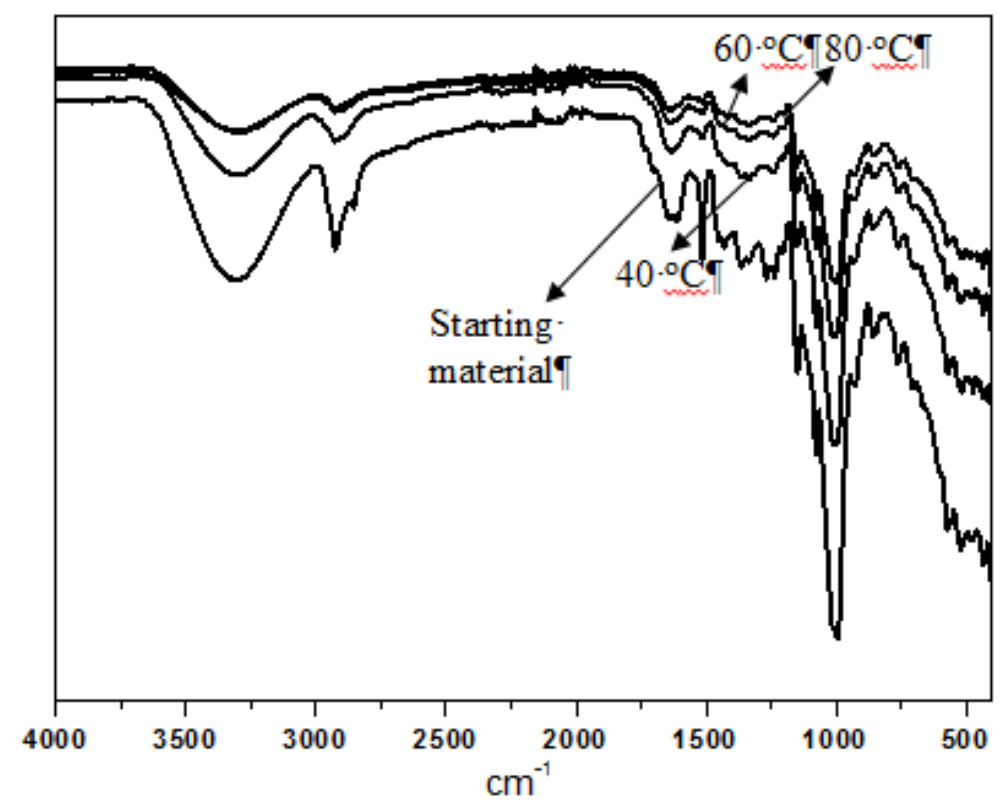

Fig. 2. FT-IR spectrum of grains of paradise before and after treatment by $\mathrm{SCCO}_{2}$ at pressure of $30 \mathrm{MPa}$.

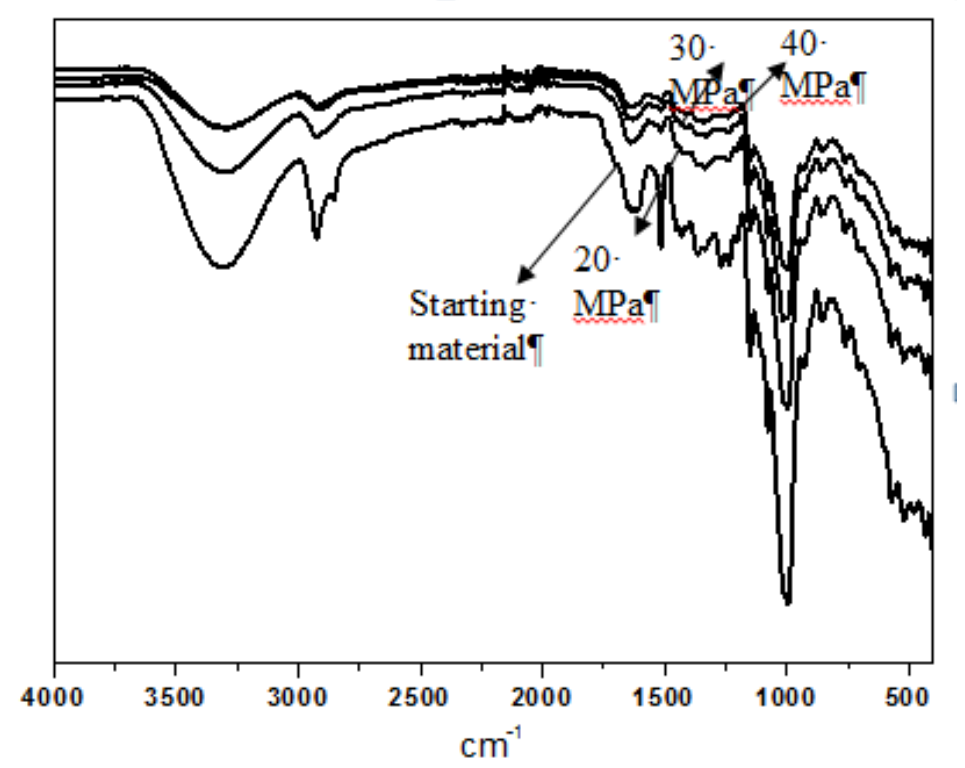

Fig. 3. FT-IR spectrum of grains of paradise before and after treatment by $\mathrm{SCCO}_{2}$ at temperature of $40^{\circ} \mathrm{C}$.

Table 1. Wave number assignments of FTIR spectra.

\begin{tabular}{ccc}
\hline $\begin{array}{c}\text { Wave number } \\
{\left[\mathrm{cm}^{-1}\right]}\end{array}$ & Functional groups & Compounds \\
\hline 3305 & O-H stretching & Acid, methanol \\
2925 & $\mathrm{C}-\mathrm{H}_{\mathrm{n}}$ stretching & Alkyl, aliphatic, aromatic \\
1515 & $\mathrm{C}=\mathrm{O}$ stretching & Ketone and carbonyl \\
1613 & $\mathrm{C}=\mathrm{C}$ stretching & Aromatic skeletal mode \\
1515 & $\mathrm{C}=$ O stretching & Ketone and carbonyl \\
1149 & $\mathrm{C}-\mathrm{O}-\mathrm{C}$ stretching vibration & Pyranose ring skeletal \\
1076 & C-O stretching and C-O & C-OH (ethanol) \\
& deformation & \\
995 & C-N stretching & aliphatic amine \\
\hline
\end{tabular}


Generally, in extraction process of plant biomass components including $\mathrm{SCCO}_{2}$ extraction process, the extracted components from the plant biomass matrix could be used as a critical indicator to evaluate an extraction method. This is because of the extracted components allows to represent the components obtained from plant biomass matrix by the particular extraction method. In order to understand the chemical compounds in the extract from grains of paradise seeds by $\mathrm{SCCO}_{2}$ extraction process, the extract was identified by using GC-MS. Next, the identified components of the main peaks in the GC-MS spectra were carried out by using a NIST mass spectral database. Figure 4 showed the a GC-MS chromatogram of the compound obtained from grains of paradise seeds when the $\mathrm{SCCO}_{2}$ extraction process was conducted at temperature of $40{ }^{\circ} \mathrm{C}$ and pressure of $20 \mathrm{MPa}$ with $15 \mathrm{~min}$ extraction time. The list of identified chemical compounds was showed in Table 2. The GC-MS allows to trace a number of small features indicating the presence of lower and higher molecular weight products that varied as a function of temperature. The identities of compounds determined via a match of mass spectra in the GC-MS computer library are reliable. As shown in Fig. 4, the compounds such as caryophyllene, $\alpha$-caryophyllene, $\beta$-chamigrene, $p-$ ethylguaiacol, and [0]-paradol were detected clearly. However, gingerol and shogaol as major compounds in grains of paradise seeds [23] were not detected due to the prolonged GC-MS analysis at high temperatures. Fernandez et al. 2006 [24] reported that due to thermal instability of gingerol and its derived compounds, these compounds were very rarely detected by GC-MS. The degradation of them might be occurred at the instrument injector port of GC-MS. Sonale and Kadimi 2014 [17] informed that shogaols and paradols were acquired from gingerols during thermal processing, thus they were not found in the fresh of Zingiberaceae species. Shogaols were gingerol analogues with a 4, 5 double bond, generating from elimination of 5-hydroxy groups; and the hydrogenation of shogaol may produce paradol compounds. They also informed that gingerols, shogaols, and paradols which found in the species of Zingiberaceae were homologous series of phenolic ketones and paradols was more stable than gingerols and shogaols. Hence, only paradol compounds were identified by GC-MS.

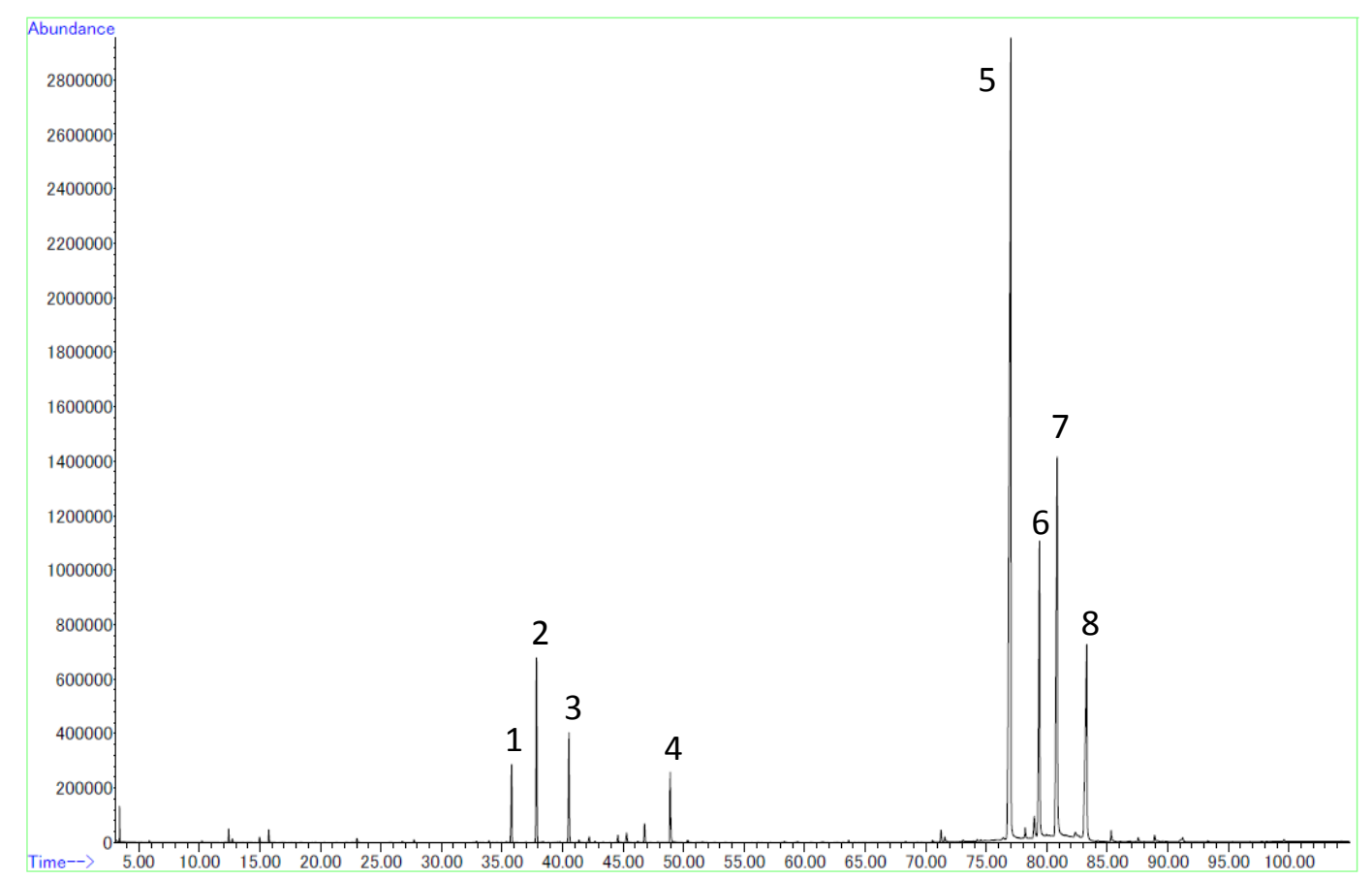

Fig. 4. A typical of GC-MS chromatogram of the grains of paradise extract. 
Table 2. Identified chemical compounds of the grains of paradise extract.

\begin{tabular}{|c|c|c|c|c|}
\hline No & $\begin{array}{l}\text { Retention } \\
\text { time [min] }\end{array}$ & Compound name & Molecular weight & $\begin{array}{c}\text { Characteristic ions } \\
{[\mathrm{m} / \mathrm{q}]}\end{array}$ \\
\hline 1 & 35.79 & Caryophyllene & 204.35 & $204.0,133.1,93.1$ \\
\hline 2 & 37.86 & $\alpha$-Caryophyllene & 204.35 & 204.2, 121.1, 93.1 \\
\hline 3 & 40.53 & $\beta$-Chamigrene & 204.35 & $204.2,189.1,93.1$ \\
\hline 4 & 48.90 & Unknown & - & - \\
\hline 5 & 76.40 & [0]-Paradol & 194.23 & $194.0,137.1,179.1$ \\
\hline 6 & 79.40 & [0]-Paradol & 194.23 & $194.0,137.1,205.1$ \\
\hline 7 & 80.86 & $p$-Ethylguaiacol & 152.19 & $152.0,180.0,292.2$ \\
\hline 8 & 83.30 & [0]-Paradol & 194.23 & $194.0,137.1,294.2$ \\
\hline
\end{tabular}

In order to quantify the amount of gingerol (6-gingerol), shogaol (6-shogaol), and paradol (6-paradol) in the extracts, they were analyzed by high-performance liquid chromatography (HPLC). Figure 5 showed the HPLC chromatograms of extract grains of paradise seeds by $\mathrm{SCCO}_{2}$ when the extraction was conducted at temperature of $80{ }^{\circ} \mathrm{C}$ and pressure of $20 \mathrm{MPa}$. There are many grains of paradise seeds components could be extracted from grains of paradise seeds sample. However, in this work, gingerol, shogaol, and paradol were subjected as target compounds and would be determined quantitatively. Gingerol, shogaol, and paradol in the extracts which trapped in $10 \mathrm{ml}$ of ethanol were filtered using a disposable filter of $0.45 \mu \mathrm{m}$ pore size prior to HPLC analysis. Then, they were directly injected into HPLC equipment. Initially, the pure compound of gingerol or shogaol or paradol diluted in ethanol as a standard was injected in the HPLC system to make calibration curve in 5 point. Next, the amount of each standard leaving the HPLC column will assign the intensity of the signal generated in the detector. By comparing the time it takes for the peak to show up (the retention time) with the retention times for the standard, the amount of gingerol or shogaol or paradol in the extract can be quantified. This analysis can be performed with good precision; therefore, other methods analysis was not carried out.

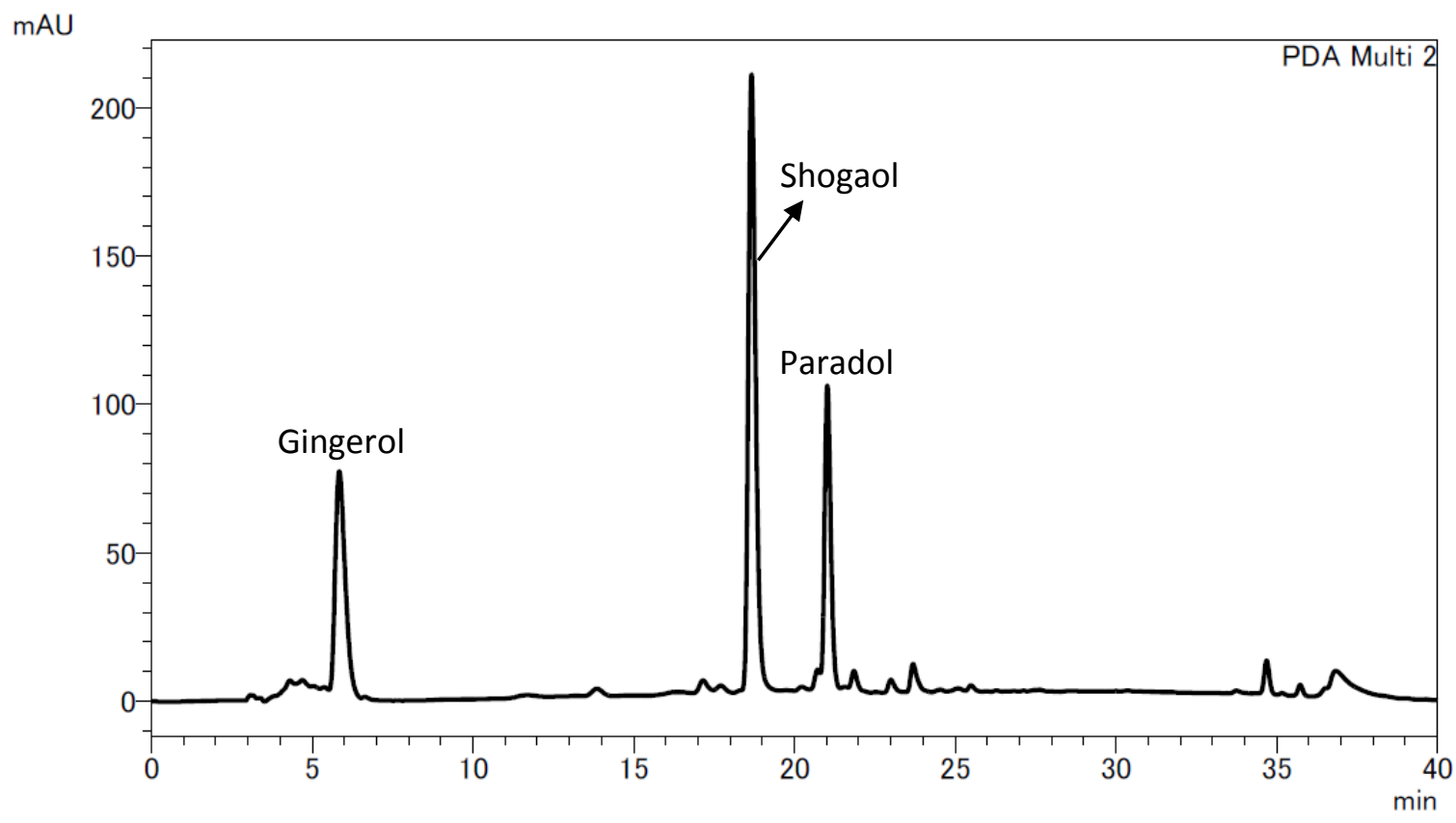

Fig. 5. HPLC chromatogram of extracted compounds.

Figure 6 showed the amount of extracts from grains of paradise seeds at various extraction conditions. Obviously, the yields of gingerol, shogaol and paradol differ at different conditions. Figure 6(a) shows the 
influences of extraction pressures on the yields of gingerol, shogaol and paradol at temperature of $80{ }^{\circ} \mathrm{C}$. The yields of them increased clearly with increasing extraction pressures. At $20 \mathrm{MPa}$, the yields of gingerol, shogaol and paradol are 1.66, 1.07, and $1.39 \mathrm{mg} / \mathrm{g}$ sample, respectively. They increase significantly to 8.12 , 3.74 , and $3.93 \mathrm{mg} / \mathrm{g}$ sample when the extraction pressure is increased to $30 \mathrm{MPa}$. These results might be related to the density of $\mathrm{CO}_{2}$ that affect to solubility and dissolution capacity of $\mathrm{SCCO}_{2}$, where, increasing of $\mathrm{CO}_{2}$ density allows the increasing of extract yields [25-27]. The density of $\mathrm{CO} 2$ was $0.59 \mathrm{~g} / \mathrm{cm}^{3}$ at $80{ }^{\circ} \mathrm{C}$ and $20 \mathrm{MPa}$, then it increased to $0.75 \mathrm{~g} / \mathrm{cm}^{3}$ at $30 \mathrm{MPa}$ with the same temperature. It was clearly that the density of $\mathrm{CO}_{2}$ can be significantly increased by increasing pressure at a constant temperature lead to an increase in the dissolving capacity of $\mathrm{SCCO}_{2}$ and gives in a beneficial effect on the extraction process. Shi $e t$ al. 2009 [26] studied the effects of pressure and temperature on the solubility of lycopene in $\mathrm{SCCO}_{2}$ media. They concluded that increasing the $\mathrm{CO}_{2}$ density at a constant temperature showed a distinct increase in solubility. However, a higher solvation power at higher pressure of $\mathrm{SCCO}_{2}(40 \mathrm{MPa})$ may be associated with lower selectivity [25, 28].
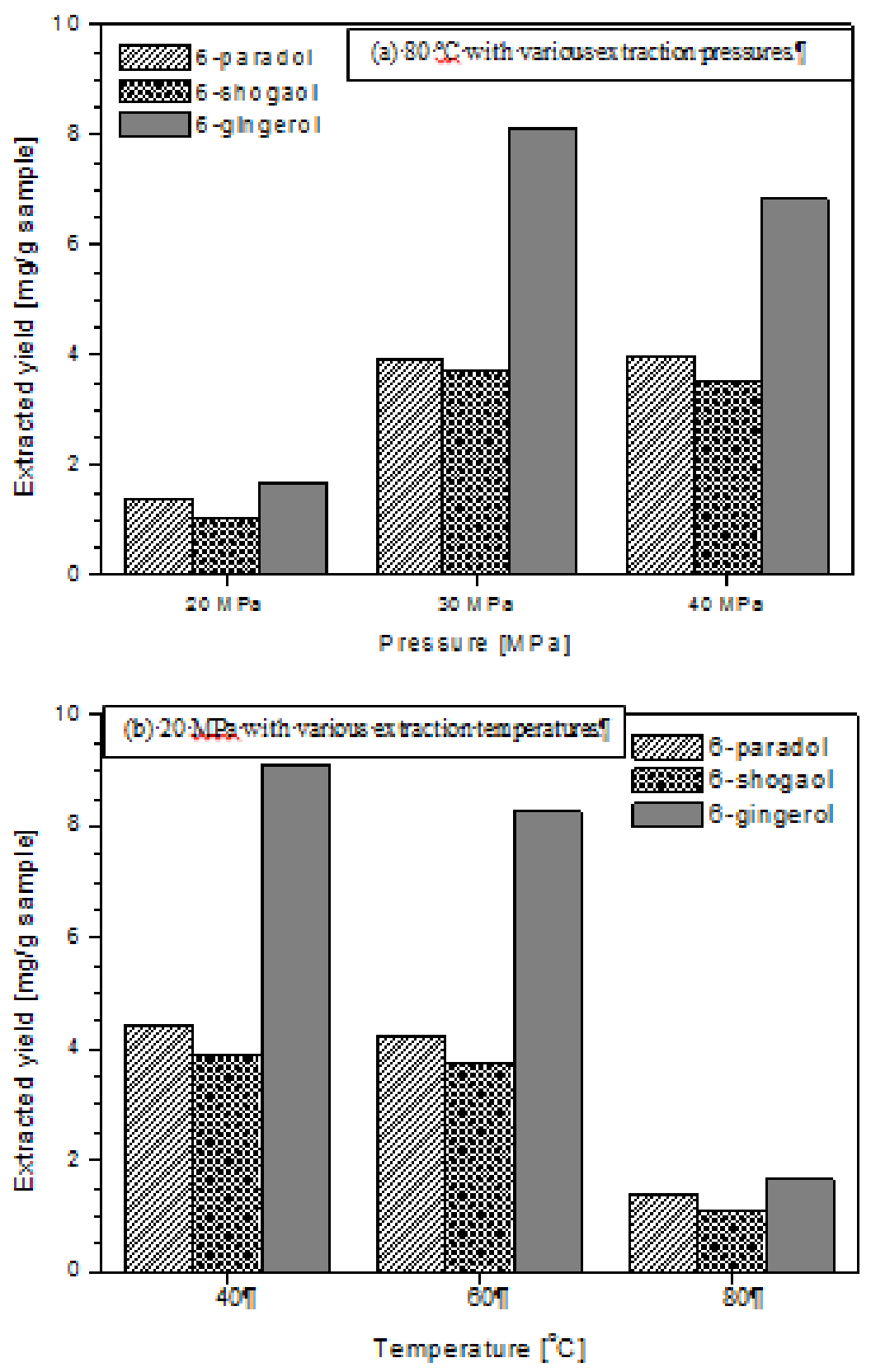

Fig. 6. Yields of gingerol, shogaol, and paradol at various extraction conditions. 
At higher densities, the $\mathrm{SCCO}_{2}$ is able to contact more surface area, thus resulting more grains of paradise seeds substances to dissolve and be extracted. Consequently, the yields of gingerol, shogaol and paradol seem constant or slightly decrease when the density of $\mathrm{CO}_{2}$ increases to $0.82 \mathrm{~g} / \mathrm{cm}^{3}$. They are 6.84 , 3.53 , and $3.97 \mathrm{mg} / \mathrm{g}$ sample, respectively. Peterson et al. 2006 [28] investigated the supercritical fluid extraction of geranium essential oil from geranium using $\mathrm{SCCO}_{2}$ media at temperatures of $40-70{ }^{\circ} \mathrm{C}$ and pressures of $10-30 \mathrm{MPa}$. They informed that the decreasing extraction yield with increasing pressure is explained in terms of competition between solvent density and solute vapor pressure. At these conditions the change in solvent density becomes smaller and the change in solute vapor pressure becomes more effective and can easily overcome the effect of solvent density change on the extraction yield.

Despite, the density has high effect on the solvent power of $\mathrm{SCCO}_{2}$ media, the ability of $\mathrm{SCCO}_{2}$ solvent extracting also increases with density increase at a certain temperature, or increases with temperature elevate at a certain density [25]. Reverchon and De Marco 2006 [25] explained that extraction pressure is the most important parameter that affects the selectivity and solvent power of $\mathrm{SCCO}_{2}$ extraction media which in turn determine the yield of the target substance. However, they also reported that extraction temperature is also the key parameter in the $\mathrm{SCCO}_{2}$ extraction of substances from various matrices. Figure 6(b) shows the effects of extraction temperatures on the yields of gingerol, shogaol and paradol at pressure of $20 \mathrm{MPa}$. They decreased clearly with increasing extraction temperatures. At $40{ }^{\circ} \mathrm{C}$, the yields of gingerol, shogaol and paradol are $9.12,3.90$, and $4.42 \mathrm{mg} / \mathrm{g}$ sample, respectively. At $80{ }^{\circ} \mathrm{C}$, they decreased significantly to $1.66,1.07$, and $1.39 \mathrm{mg} / \mathrm{g}$ sample, respectively. Again, these results also might be attributed to the density of $\mathrm{CO}_{2}$ as an extraction solvent, where, increasing extraction temperatures at the same extraction pressure follow by decreasing of $\mathrm{CO}_{2}$ density. Consequently, the ability of $\mathrm{SCCO}_{2}$ to extract substances from grains of paradise seeds decreases. Similar results were also reported by Machmudah et al. 2012 [29]. They studied the effect of $\mathrm{SCCO}_{2}$ extraction temperature on the $\beta$-carotene recovery extracted from tomato peel by-product. The results showed that $\beta$-carotene recovery decreased with increasing extraction temperature at a constant pressure. Ghoreishi et al. 2012 [30] informed that the effect of extraction temperature in $\mathrm{SCCO}_{2}$ extraction system is more complex due to the competition of two variables, solvent density and vapor pressure. The decrease in solvent density may reduce the solute solubility, while the vapor pressure of the solute elevates with temperature, causing an increase in solubility. The dominant effects of them affected by the system that used as an extraction process. In this study, the effect of $\mathrm{CO}_{2}$ density seems to have a high effect on the extraction yield.
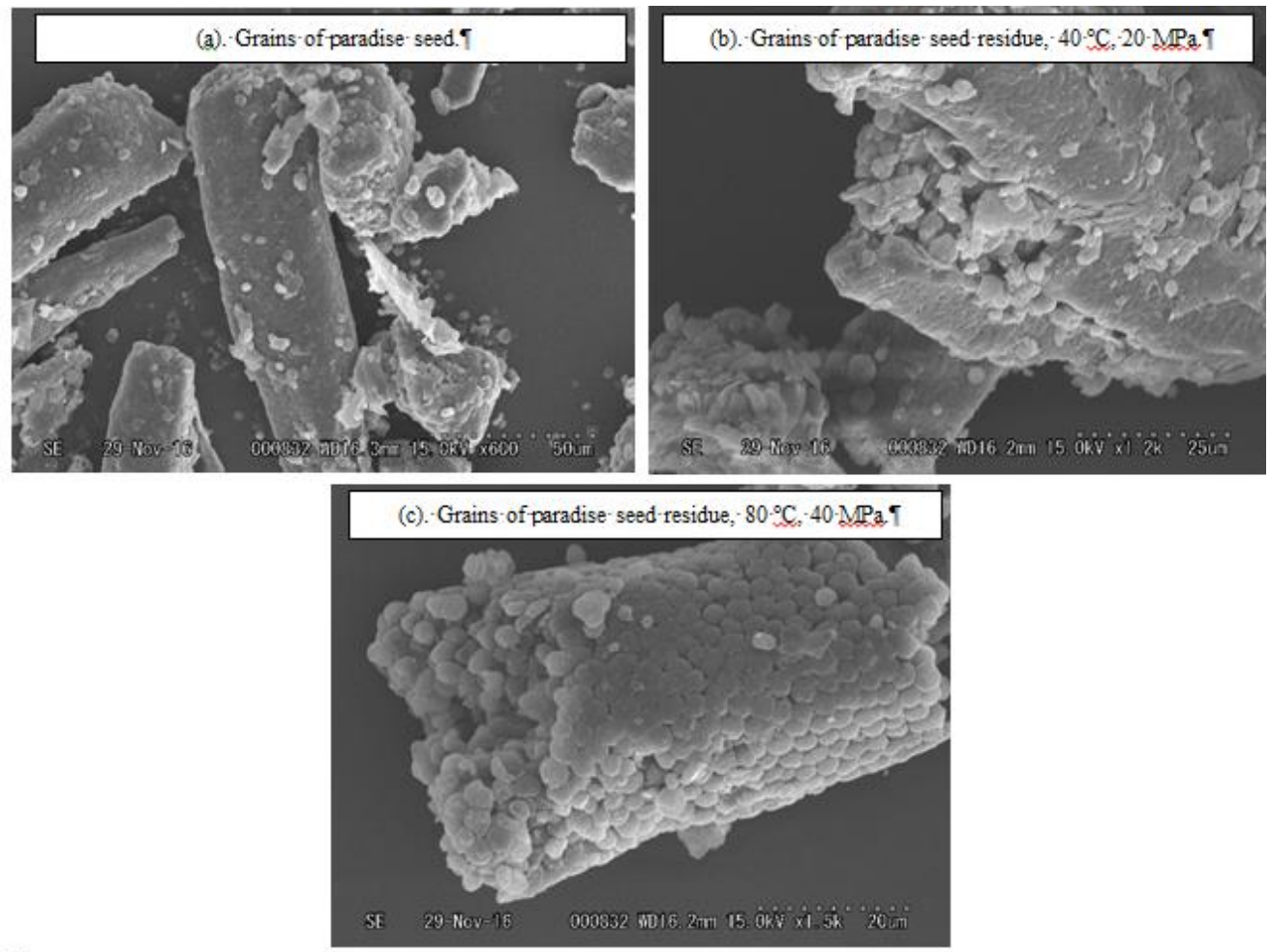

Fig. 7. SEM micrographs of grains of paradise seeds before and after treatment by $\mathrm{SCCO}_{2}$. 
When a plant matrix is placed in the organic solvent, a static film of solvent surrounding the plant cell would be generated as a result of the interactions between solvent molecules and the plant matrix cell wall substances [31]. Next, the organic solvent diffuses via the cell membrane into the plant matrix cell to form the complexes of organic solvent-plant matrix substances. As a result, the plant matrix substances might be extracted from the plant matrix cell and remain dissolved in the organic solvent. Similar phenomenon may occur when $\mathrm{SCCO}_{2}$ was contacted with grains of paradise seeds. Here, $\mathrm{SCCO}_{2}$ was flowed via high pressure pump into the extractor from the bottom and passes upwards through the grains of paradise seeds packed bed. At these conditions, $\mathrm{SCCO}_{2}$ rapidly diffuses into the grains of paradise cell and then $\mathrm{SCCO}_{2}$ may dissolve grains of paradise seeds substances via the formation of grains of paradise seeds substance- $-\mathrm{CO}_{2}$ complexes through van der Waals interactions [31]. Due to this interaction, when the $\mathrm{SCCO}_{2}$ leaves the grains of paradise seeds packed bed, the grains of paradise seeds substances might be also left this packed bed simultaneously. In the next process, when the extraction pressure was reduced until $\mathrm{CO}_{2}$ returns to the gaseous state, the grains of paradise seeds substances extract may be collected and dissolved in ethanol as a trapped solvent in the sample collection. To investigate the effect of $\mathrm{SCCO}_{2}$ that penetrates in grains of paradise seeds, the grains of paradise seeds residues were characterized by SEM. Figure 7 shows the representative SEM micrographs of grains of paradise seeds before and after $\mathrm{SCCO}_{2}$ extraction treatment. Clearly, the different of surface structures of the grains of paradise seeds before and after $\mathrm{SCCO}_{2}$ extraction treatment were found. Before $\mathrm{SCCO}_{2}$ extraction treatment, the surface morphology of grains of paradise seeds seem covered by the membrane-like structure. Therefore, they were smooth and tight with some boundary edges clearly. They did not exhibit the presence of any pores or surface cracks. After treatment by $\mathrm{SCCO}_{2}$ extraction, the physical structures disruption of the grains of paradise seeds were found and clearly observed at each condition. Apparently, $\mathrm{SCCO}_{2}$ may rupture the physical structural barriers of the grains of paradise seeds and remove their components. The increasing pressure and temperature (Fig. 7(c)) seem to an increase of $\mathrm{CO}_{2}$ diffusivity into the grains of paradise seeds and allow a more powerful swelling action to remove the substances in grains of paradise seeds [21]. Sovova 1994 [32] reported that $\mathrm{SCCO}_{2}$ has ability to rupture cells or the outer surface of matrix to access the solute substances. In detail, the $\mathrm{SCCO}_{2}$ extraction mechanism can be divided into three steps controlled by different mass transfer mechanisms [33]. They are a constant extraction rate period, a falling extraction rate period, and the diffusion controlled rate period. These steps were also initiated by the easily accessible covering solute on the external surface of the matrix. Judging these SEM micrographs, it could be said that the physical changes of the grains of paradise seeds surface happened after $\mathrm{SCCO}_{2}$ extraction treatment.

\section{Conclusions}

$\mathrm{SCCO}_{2}$ has been used as a medium for gingerol, shogaol, and paradol extraction grains of paradise seeds at temperatures of $40-80{ }^{\circ} \mathrm{C}$ and pressures of $20-40 \mathrm{MPa}$ using a semi-continuous flow-type system. Due to the combination between high diffusivity and high solvent strength of $\mathrm{SCCO}_{2}$ that can be easily adjusted by changing of temperature and/or pressure, $\mathrm{SCCO}_{2}$ became an attractive extraction medium. FT-IR spectra indicated that $\mathrm{SCCO}_{2}$ can extract the grains of paradise seeds substances. The SEM micrographs also showed that the physical changes of the grains of paradise seeds surface occurred after $\mathrm{SCCO}_{2}$ extraction. The main compounds in extracts were gingerols, shogaols, and paradols. Since these compounds are homologous series of phenolic ketones and paradols was more stable than gingerols and shogaols, the GC-MS may only detect paradol compounds. The yields of gingerols, shogaols, and paradols were affected by extraction temperatures and/or extraction pressures.

\section{Acknowledgements}

This research was supported by a grant from the Precursory Research for Embryonic Science and Technology Program of the Japan Science and Technology Agency (JST). 


\section{References}

[1] M. M. Iwu, Handbook of African Medicinal Plants, 2nd ed. New York: CRC Press Taylor \& Francis Group, 2014, pp. 123.

[2] A. Khoddami, M. A. Wilkes, and T. H. Roberts, "Techniques for analysis of plant phenolic compounds," Molecules, vol. 18, no. 2, pp. 2328-2375, Feb. 2013.

[3] R. Y. Gan, Z. Q. Deng, A. X. Yan, N. P. Shah, W. Y. Lui, C. L. Chan, and H. Corke, "Pigmented edible bean coats as natural sources of polyphenols with antioxidant and antibacterial effects," LWT - Food Sci. Technol., vol. 73, pp. 168-177, Nov. 2016.

[4] X. Fernandez, C. Pintaric, L. Lizzani-Cuvelier, A.M. Loiseau, A. Morello, and P. Pellerin, "Chemical composition of absolute and supercritical carbon dioxide extract of Aframomum melegueta," Flavour Frag. J., vol. 21, no. 1, pp. 162-165, Jan. 2006.

[5] M. Iwami, F. A. Mahmoud, T. Shiina, H. Hirayama, T. Shima, J. Sugita, and Y. Shimizu, "Extract of grains of paradise and its active principle 6-paradol trigger thermogenesis of brown adipose tissue in rats," Auton. Neurosci., vol. 161, no. 1, pp. 63-67, Apr. 2011.

[6] Y. Kawamoto, Y. Ueno, E. Nakahashi, M. Obayashi, K. Sugihara, S. Qiao, M. Iida, M. Y. Kumasaka, I. Yajima, Y. Goto, N. Ohgami, M. Kato, and K. Takeda, "Prevention of allergic rhinitis by ginger and the molecular basis of immunosuppression by 6-gingerol through T cell inactivation," J. Nutr. Biochem., vol. 27, pp. 112-122, Jan. 2016.

[7] S.M. Kim, C. Kim, H. Bae, J.H. Lee, S.H. Baek, D. Nam, W.S. Chung, B.S. Shim, S.G. Lee, S.H. Kim, G. Sethi, K.S. Ahn, "6-Shogaol exerts anti-proliferative and pro-apoptotic effects through the modulation of STAT3 and MAPKs signaling pathways," Mol. Carcinog., vol. 54, no. 10, pp. 1132-1146, Oct. 2015.

[8] A. Saha, J. Blando, E. Silver, L. Beltran, J. Sessler, and J. DiGiovanni, "6-Shogaol from dried ginger inhibits growth of prostate cancer cells both in vitro and in vivo through inhibition of STAT3 and NF- $x$ B signaling," Cancer Prev. Res., vol. 7, no. 6, pp. 627-638, Jun. 2014.

[9] Y. Zhou, Q. Tang, S. Zhao, F. Zhang, L. Li, W. Wu, Z. Wang, and S. Hann, "Targeting signal transducer and activator of transcription 3 contributes to the solamargine-inhibited growth and induced apoptosis of human lung cancer cells," Tumor Biol., vol. 35, no. 8, pp. 8169-8178, Dec. 2014.

[10] S. Machmudah, A. Shotipruk, M. Goto, M. Sasaki, and T. Hirose, "Extraction of astaxanthin from Haematococcus pluvialis using supercritical $\mathrm{CO}_{2}$ and ethanol as entrainer," Ind. Eng. Chem. Res., vol. 45, no. 10, pp. 3652-3657, May 2006.

[11] K. Kitada, S. Machmudah, M. Sasaki, M. Goto, Y. Nakashima, S. Kumamoto, and T. Hasegawa, "Supercritical $\mathrm{CO}_{2}$ extraction of pigment components with pharmaceutical importance from Chlorella vulgaris," J. Chem. Technol. Biotechnol., vol. 84, no. 5, pp. 657-661, May 2009.

[12] D. Ruen-ngam, A. Shotipruk, P. Pavasant, S. Machmudah, and M. Goto, "Selective extraction of lutein from alcohol treated Chlorella vulgaris by supercritical $\mathrm{CO}_{2}$," Chem. Eng. Technol., vol. 35, no. 2, pp. 255-260, Feb. 2012.

[13] H. Kanda, Y. Kamo, S. Machmudah, Wahyudiono, and M. Goto, "Extraction of fucoxanthin from raw macroalgae excluding drying and cell wall distuption by liquefied dimethyl ether," Mar. Drugs, vol. 12, no. 5, pp. 2383-2396, Apr. 2014.

[14] M. Goto, H. Kanda, Wahyudiono, and S. Machmudah, "Extraction of carotenoids and lipids from algae by supercritical $\mathrm{CO}_{2}$ and subcritical dimethyl ether," J. Supercrit. Fluids, vol. 96, pp. 245-251, Jan. 2015.

[15] S. Machmudah, T. Izumi, M. Sasaki, and M. Goto, "Extraction of pungent components from Japanese pepper (Xanthoxylum piperitum DC.) using supercritical $\mathrm{CO}_{2}$," Sep. Pur. Technol., vol. 68, no. 2, pp. 159-164, Aug. 2009.

[16] M. E. Leblebici, S. Machmudah, M. Sasaki, and M. Goto, "Antiradical efficiency of essential oils from plant seeds obtained by supercritical $\mathrm{CO}_{2}$, soxhlet extraction, and hydrodistillation," Sep. Sci. Technol., vol. 48, no. 2, pp. 328-337, Aug. 2012.

[17] R. S. Sonale and U. S Kadimi, "Characterization of gingerol analogues in supercritical carbon dioxide (SC $\mathrm{CO}_{2}$ ) extract of ginger (Zingiber officinale, R.,)," J. Food Sci. Technol., vol. 51, no. 11, pp. 3383-3389, Nov. 2014.

[18] S. Machmudah, A. Martin, M. Sasaki, and M. Goto, "Mathematical modeling for simultaneous extraction and fractionation process of coffee beans with supercritical $\mathrm{CO}_{2}$ and water," J. Supercrit. Fluids, vol. 66, pp. 111-119, Jun. 2012. 
[19] K. Tomitaa, S. Machmudah, Wahyudiono, R. Fukuzato, H. Kanda, A. T. Quitain, M. Sasaki, and M. Goto, "Extraction of rice bran oil by supercritical carbon dioxide and solubility consideration," Sep. Pur. Technol., vol. 125, pp. 319-325, Apr. 2014.

[20] Y. Matsunaga, Wahyudiono, S. Machmudah, M. Sasaki, and M. Goto, "Hot compressed water extraction of polysaccharides from Ganoderma lucidum using a semibatch reactor," Asia Pac. J. Chem. Eng., vol. 9, no. 1, pp. 125-133, Jan. 2014.

[21] S. Kodama, T. Shoda, S. Machmudah, Wahyudiono, H. Kanda, and M. Goto, "Enhancing pressurized water extraction of b-glucan from barley grain by adding $\mathrm{CO}_{2}$ under hydrothermal conditions," Chem. Eng. Process. Process Intensif., vol. 97, pp. 45-54, Nov. 2015.

[22] M. Herrero, J. A. Mendiola, A. Cifuentes, and E. Ibanez, "Supercritical fluid extraction: Recent advances and applications," J. Chromatogr. A, vol. 1217, no. 16, pp. 2495-2511, Apr. 2010.

[23] N. Ilic, B. M. Schmidt, A. Poulev, and I. Raskin, "Toxicological evaluation of grains of paradise (Aframomum melegueta) [Roscoe] K. Schum”, J. Ethnopharmacol., vol. 127, no. 2, pp. 352-356, Feb. 2010.

[24] X. Fernandez, C. Pintaric, L. Lizzani-Cuvelier, A. M. Loiseau, A. Morello, and P. Pellerin, "Chemical composition of absolute and supercritical carbon dioxide extract of Aframomum melegueta," Flavour Frag. J., vol. 21, no. 1, pp. 162-165, Jan. 2006.

[25] E. Reverchon and I. De Marco, "Supercritical fluid extraction and fractionation of natural matter," J. Supercrit. Fluids, vol. 38, no. 2, pp. 146-166, Sept. 2006.

[26] J. Shi, M. Khatri, S. J. Xue, G. S. Mittal, Y. Ma, and D. Li, "Solubility of lycopene in supercritical $\mathrm{CO}_{2}$ fluid as affected by temperature and pressure," Sep. Pur. Technol., vol. 66, no. 2, pp. 322-328, Apr. 2009.

[27] R. M. Couto, P. C. Simoes, A. Reis, T. L. Da Silva, V. H. Martins, and Y. Sanchez-Vicente, "Supercritical fluid extraction of lipids from the heterotrophic microalga Crypthecodinium cohnii," Eng. Life Sci., vol. 10, no. 2, pp. 158-164, Apr. 2010.

[28] A. Peterson, S. Machmudah, B. C. Roy, M. Goto, M. Sasaki, and T. Hirose, "Extraction of essential oil from geranium (Pelargonium graveolens) with supercritical carbon dioxide," J. Chem. Technol. Biotechnol., vol. 81, no. 2, pp. 167-172, Feb. 2006.

[29] S. Machmudah, S. Winardi, M. Sasaki, M. Goto, N. Kusumoto, and K. Hayakawa, "Lycopene extraction from tomato peel by-product containing tomato seed using supercritical carbon dioxide," J. Food Eng., vol. 108, no. 2, pp. 290-296, Jan. 2012.

[30] S. M. Ghoreishi, H. Kamali, H. S. Ghaziaskar, and A. A. Dadkhah, "Optimization of supercritical extraction of linalyl acetate from lavender via Box-Behnken design," Chem. Eng. Technol., vol. 35, no. 9, pp. 1641-1648, Sept. 2012.

[31] R. Halim, M. K. Danquah, and P. A. Webley, "Extraction of oil from microalgae for biodiesel production: A review," Biotechnol. Adv., vol. 30, no. 3, pp. 709-732, Jun. 2012.

[32] H. Sovova, "Rate of the vegetable oil extraction with supercritical $\mathrm{CO}_{2}$-I. Modelling of extraction curves," Chem. Eng. Sci., vol. 49, no. 3, pp. 409-414, Jan. 1994.

[33] A. Shilpi, U. S. Shivhare, and S. Basu, "Supercritical $\mathrm{CO}_{2}$ extraction of compounds with antioxidant activity from fruits and vegetables waste-A review," Focusing on Modern Food Industry, vol. 2, no. 1, pp. 43-62, Feb. 2013. 